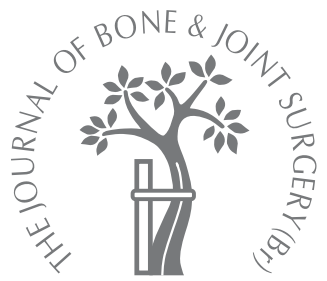
A. B. Old, B. J. McGrory, R. R. White, G. M. Babikian
From Orthopaedic Associates of Portland, Portland, USA

\title{
Fixation of Vancouver B1 peri-prosthetic fractures by broad metal plates without the application of strut allografts
}

The use of allograft struts and cerclage wire, possibly augmented by plate fixation, for the treatment of Vancouver type-B1 peri-prosthetic fractures around a total hip replacement has been strongly advocated. We examined our results using plate fixation without allograft struts and compared them with the results of the use of struts alone or when combined with plate fixation. Of 20 consecutive patients with type-B1 fractures treated by open reduction and plate fixation, 19 were available for follow-up. The fractures healed in 18 patients with a mean time to weight-bearing of ten weeks (4 to 19). There were no cases of infection or malunion. Nonunion occurred in one patient and required a second plate fixation to achieve union.

Safe, cost-effective treatment of Vancouver type-B1 fractures can be performed by plate fixation without the addition of cortical struts. This procedure may allow earlier weightbearing than allograft strut fixation alone.

Peri-prosthetic femoral fractures are becoming increasingly common and are a major complication of total hip replacement (THR). The incidence has been reported to be $1.5 \%$ for primary procedures and $4 \%$ for revisions. ${ }^{1}$ Their prevalence can be attributed to an increasing number of replacements in both younger patients and a more active elderly population with increased longevity.

Methods of treatment for these fractures are based on the general health of the patient, the location of the fracture, the stability of the femoral component and the quality of the surrounding bone. The specific treatment is controversial, but there is general agreement that surgery is indicated in most cases. The most widely-used classification for these fractures is the Vancouver system ${ }^{1}$ (Table I) and some authors have used this for a treatment algorithm. $^{2-5}$

Peri-prosthetic fractures with a well-fixed femoral component (Vancouver type-B1) are the most common and have been the subject of a recent multicentre study. ${ }^{2}$ This supported the use of cortical struts using cerclage wire, with or without the addition of a metal plate, for their surgical treatment. The authors concluded that the allograft struts were the most important part of the treatment, but they did not assess the efficacy of plate fixation without the use of cortical struts. We hypothesise that for Vancouver typeB1 fractures, with adequate bone stock, a plate alone may be preferable. We believe that this will decrease periosteal stripping and the potential transmission of disease and reduce the total cost of the procedure. It may allow earlier return to weight-bearing.
Fellow

B. J. McGrory, MD, Clinical

Associate Professor

R. R. White, MD, Chief of

Orthopaedic Trauma

G. M. Babikian, MD, Chief of

Orthopaedics

Orthopaedic Associates of

Portland, 33 Sewall Street.

Portland, Maine 04102, USA.

Correspondence should be sent to $\mathrm{Dr}$ B. J. McGrory; e-mail: mjri@yahoo.com

(C)2006 British Editorial Society of Bone and Joint Surgery doi:10.1302/0301-620X.88B11. $17749 \$ 2.00$

J Bone Joint Surg [Br] 2006;88-B:1425-9.

Received 7 February 2006;

Accepted after revision 21 June 2006

\begin{tabular}{|c|c|}
\hline $\begin{array}{l}\text { Fracture type } \\
\text { and subtype }\end{array}$ & Location and nature of fracture \\
\hline$A_{G}$ & Greater trochanteric region \\
\hline$A_{L}$ & Lesser trochanteric region \\
\hline B1 & Around or just distal to the prosthesis, implant stable \\
\hline B2 & Around or just distal to the prosthesis, implant unstable \\
\hline B3 & $\begin{array}{l}\text { Around or just distal to the prosthesis, implant unstable, } \\
\text { bone stock inadequate }\end{array}$ \\
\hline $\mathrm{C}$ & Well below prosthesis \\
\hline
\end{tabular}




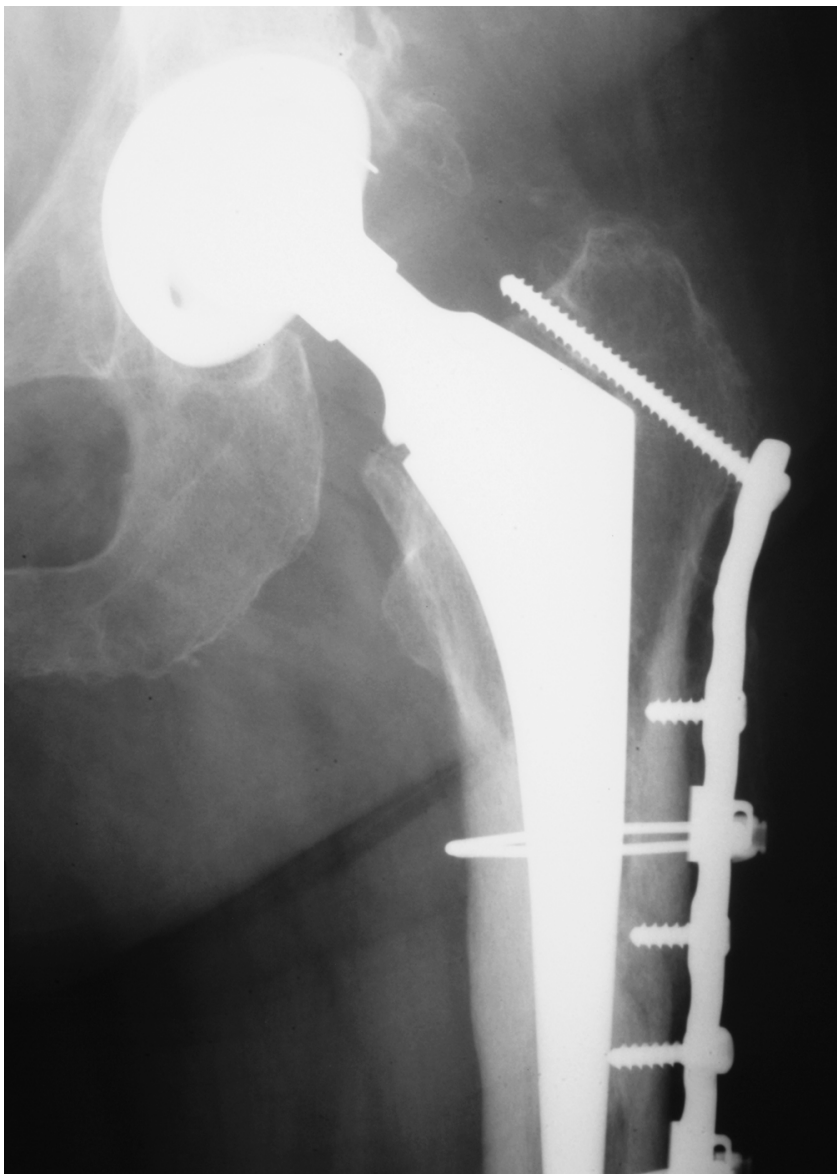

Fig. 1

Anteroposterior radiograph of the proximal femur showing placement of a screw into the greater trochanter to obtain stable fixation.

Our aim therefore was to examine our experience of treating peri-prosthetic fractures afterTHR with a wellfixed femoral component using plate fixation without allograft struts.

\section{Patients and Methods}

We retrospectively assessed 55 consecutive patients who had been treated for a peri-prosthetic femoral fracture around a THR between December 1993 and May 2005. The inclusion criteria of an acute, traumatic fracture occurring around or below a stable hip prosthesis (Vancouver type-B1) were met in 20 patients with 20 fractures. One patient died one month after operation from unrelated causes, leaving 19 available for study. In 12 the femoral component was cemented and in seven uncemented. Stability of the prosthesis was determined by accepted criteria. ${ }^{6,7}$ There were four men and 15 women with a mean age at the time of fracture of 78 years (54 to 100).

All the fractures were treated by open reduction and internal fixation. A broad dynamic compression plate (DCP; Synthes, West Chester, Pennsylvania) was used in 15 fractures and a locking compression plate (Synthes) in the other four. Supplementary proximal cerclage wiring (Zimmer Cable Ready System; Zimmer Inc., Warsaw, Indiana) was used in ten patients with eyelet attachments (Synthes), to attach the cables to the plate. The broad plates allowed for screw placement around the stem if needed. A commercial cable plate system was not used. No allograft struts or other bone graft were used since the host bone stock was found to be sufficient. All the operations were performed by three experienced trauma surgeons (BJM, RRW, GMB) at one trauma centre.

At operation, each patient was placed in the lateral position and the fracture was exposed through a lateral incision. This incorporated the original primary hip incision if required. The gluteal fascia and fascia lata were incised longitudinally and gluteus maximus separated in the direction of its fibres. Vastus lateralis was reflected anteriorly to expose the site of the fracture and to allow the plate to be placed along the lateral cortex. Pointed reduction forceps were then introduced through the soft tissues without muscle stripping. Loose fragments of cement were removed from the fracture site in one of the 12 patients with cemented prostheses. Periosteal stripping was kept to an absolute minimum to preserve the blood supply. The fracture was reduced and maintained by reduction forceps. The plate was contoured appropriately before placement of bicortical screws distal to the prosthesis in the standard fashion. By careful positioning, bicortical screws could often be placed anterior or posterior to the stem of the prosthesis. Unicortical screws were used if bicortical fixation could not be achieved. If the plate extended a long way proximally, one or more screws could be angled caudally into the greater trochanter (Fig. 1). Screw fixation above the lesser trochanter was performed in 11 patients (bicortical in seven, unicortical in three and bicortical and unicortical in one). The length of the plate was determined based on the pattern of the fracture, but longer plates were favoured to dissipate torsional, lateral bending and axial forces (Table II). Supplementary cables were used primarily when we were unable to use three or more bicortical screws and were confined to the proximal end of the plate, away from the site of the fracture, thereby avoiding additional soft-tissue stripping near the fracture.

Post-operative rehabilitation was specific to each patient, but early range of movement exercises were common to all. The times to weight-bearing varied depending on the patients' general health and their pre-operative mobility. Weight-bearing was usually allowed when fracture callus was visible radiologically and the application of weight was painfree. Union was considered to have occurred when there was radiological evidence of bone bridging and remodelling on both anteroposterior (AP) and lateral radiographs, and weight-bearing was entirely without discomfort. Peri-operative infection, nonunion and/or malunion were noted. Femoral alignment was measured using the post-operative films taken on the date when the patient was determined as being healed. Malunion was defined as dis- 
Table II. Data for the 20 patients treated by plate fixation for Vancouver type-B1 peri-prosthetic fractures after total hip replacement

\begin{tabular}{|c|c|c|c|c|c|c|}
\hline Case & $\begin{array}{l}\text { Age } \\
\text { (yrs) }\end{array}$ & Gender & Side & Plate* & $\begin{array}{l}\text { Time to weight-bearing } \\
\text { (wks) }\end{array}$ & $\begin{array}{l}\text { Cemented femoral } \\
\text { component }\end{array}$ \\
\hline 1 & 85 & $\mathrm{M}$ & $\mathrm{R}$ & $4.5 \mathrm{~mm}$, broad LC-DCP, 18 hole & 19 & No \\
\hline 2 & 85 & $\mathrm{M}$ & $\mathrm{R}$ & $4.5 \mathrm{~mm}, \mathrm{LCP}, 10$ hole & 6 & Yes \\
\hline 3 & 81 & $\mathrm{~F}$ & $\mathrm{~L}$ & $4.5 \mathrm{~mm}$, broad LC-DCP, 14 hole & 4 & Yes \\
\hline 4 & 86 & $\mathrm{~F}$ & $\mathrm{R}$ & $4.5 \mathrm{~mm}$, broad LCP, 14 hole & 8 & Yes \\
\hline 5 & 80 & $\mathrm{~F}$ & $\mathrm{R}$ & $4.5 \mathrm{~mm}, \mathrm{LCP}$ condylar, 12 hole & 9 & Yes \\
\hline 6 & 79 & $\mathrm{~F}$ & $\mathrm{~L}$ & $4.5 \mathrm{~mm}$, LCP condylar, 16 hole & 8 & Yes \\
\hline 7 & 54 & $\mathrm{~F}$ & $\mathrm{R}$ & $4.5 \mathrm{~mm}$, broad LC-DCP, 12 hole & 14 & No \\
\hline 8 & 89 & $\mathrm{~F}$ & $\mathrm{~L}$ & $4.5 \mathrm{~mm}$, broad DCP, 12 hole & 10 & No \\
\hline 9 & 75 & $\mathrm{~F}$ & $\mathrm{R}$ & $4.5 \mathrm{~mm}$, broad DCP, 16 hole & 8 & No \\
\hline 10 & 91 & $\mathrm{~F}$ & $\mathrm{~L}$ & $4.5 \mathrm{~mm}$, broad LC-DCP, 16 hole & Deceased (unrelated to surgery) & Yes \\
\hline 11 & 68 & $\mathrm{M}$ & $\mathrm{L}$ & $4.5 \mathrm{~mm}$, broad LC-DCP, 14 hole & 17 & Yes \\
\hline 12 & 72 & $\mathrm{~F}$ & $\mathrm{~L}$ & $4.5 \mathrm{~mm}$, broad LC-DCP, 14 hole & 9 & Yes \\
\hline 13 & 70 & $\mathrm{~F}$ & $\mathrm{R}$ & $4.5 \mathrm{~mm}$, broad LC-DCP, 16 hole & Nonunion & Yes \\
\hline 14 & 76 & $\mathrm{~F}$ & $\mathrm{R}$ & $4.5 \mathrm{~mm}$, broad DCP, 16 hole & 6 & No \\
\hline 15 & 100 & $\mathrm{~F}$ & $\mathrm{R}$ & $4.5 \mathrm{~mm}$, broad LC-DCP, 14 hole & 9 & No \\
\hline 16 & 74 & $\mathrm{~F}$ & $\mathrm{R}$ & $4.5 \mathrm{~mm}$, broad LC-DCP, 14 hole & 13 & Yes \\
\hline 17 & 79 & $\mathrm{~F}$ & $\mathrm{~L}$ & $4.5 \mathrm{~mm}$, broad LC-DCP, 20 hole & 12 & Yes \\
\hline 18 & 80 & $\mathrm{~F}$ & $\mathrm{~L}$ & $4.5 \mathrm{~mm}$, broad LC-DCP, 18 hole & 9 & No \\
\hline 19 & 80 & $\mathrm{M}$ & $\mathrm{R}$ & $4.5 \mathrm{~mm}, \mathrm{LC}-\mathrm{DCP}, 9$ hole & 10 & Yes \\
\hline 20 & 76 & $\mathrm{~F}$ & $\mathrm{R}$ & $4.5 \mathrm{~mm}, \mathrm{LCP}$ condylar, 12 hole & 9 & Yes \\
\hline
\end{tabular}

* LC-DCP, limited contact-dynamic compression plate; LCP, locking compression plate; DCP, dynamic compression plate

placement exceeding $5^{\circ}$ in either the AP or mediolateral planes. Rotatory malunion was defined as displacement of more than $5^{\circ}$ compared with the contralateral leg on clinical examination.

Fractures were retrospectively classified using the Vancouver system ${ }^{1}$ (Table I), although the treatment algorithm suggested by Brady et $\mathrm{al}^{8}$ was not applied at the time of surgery.

Follow-up was performed by the three operating surgeons except in three patients in whom the time to full healing was judged from notes and radiographs taken at the referral practice. The mean length of follow-up was 95 weeks (16 to 369 ).

Statistical analysis. Our results were compared with historical control findings ${ }^{2}$ and a statistical comparison using Fisher's exact test for nominal variable comparison. Statistical significance was reported as a p-value of less than 0.05 .

\section{Results}

Union occurred in 18 patients without malunion or infection (Fig. 2). The mean time to weight-bearing for these patients was ten weeks (4 to 19) (Table II).

One patient developed nonunion which united uneventfully with anatomical alignment following further fixation (Fig. 3).

In one patient with a healed peri-prosthetic fracture a subsequent stress fracture occurred at a different site, which was treated by a second plate fixation. This stress fracture was thought to have been due to varus placement of the femoral component and was unrelated to the original fixation of the fracture.

We compared our results with the two groups described by Haddad et $\mathrm{al}^{2}$ (strut allograft alone and strut allograft

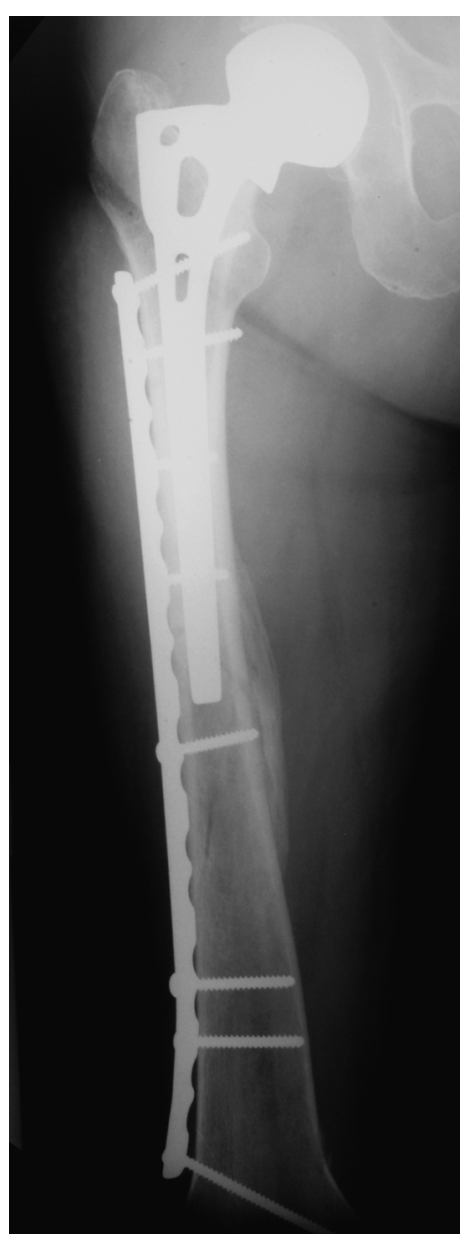

Fig. 2

Case 9. Anteroposterior radiograph eight weeks after plate fixation of a peri-prosthetic femoral fracture. A $4.5 \mathrm{~mm}, 16$ hole dynamic compression plate was used to dissipate torsional and lateral bending, as well as axial forces. There is obvious bone bridging and remodelling medially. 


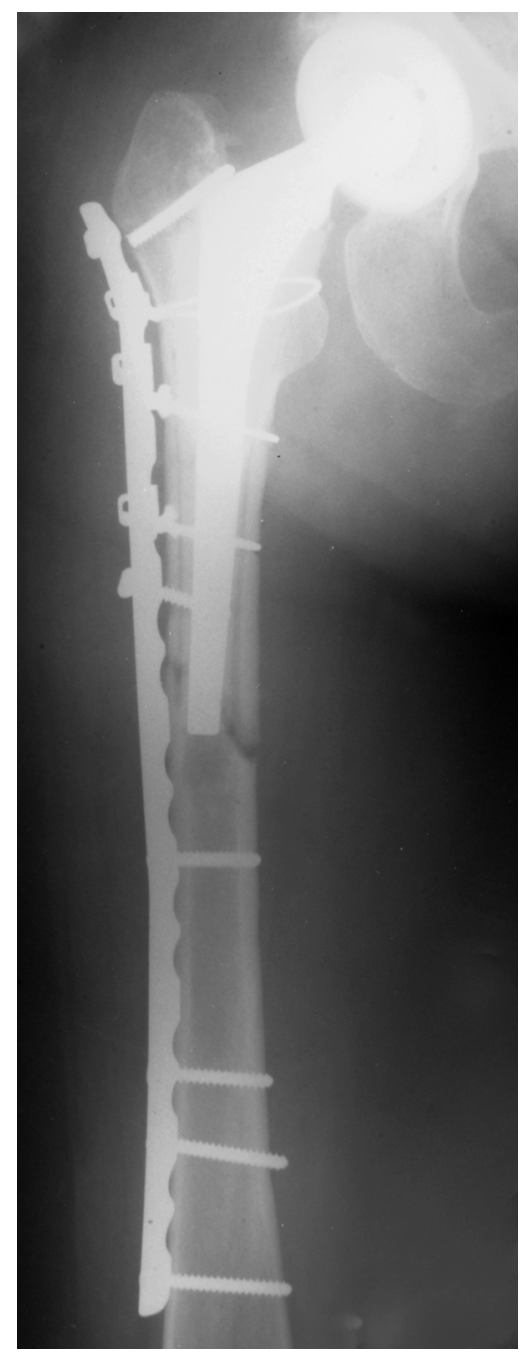

Fig. 3a

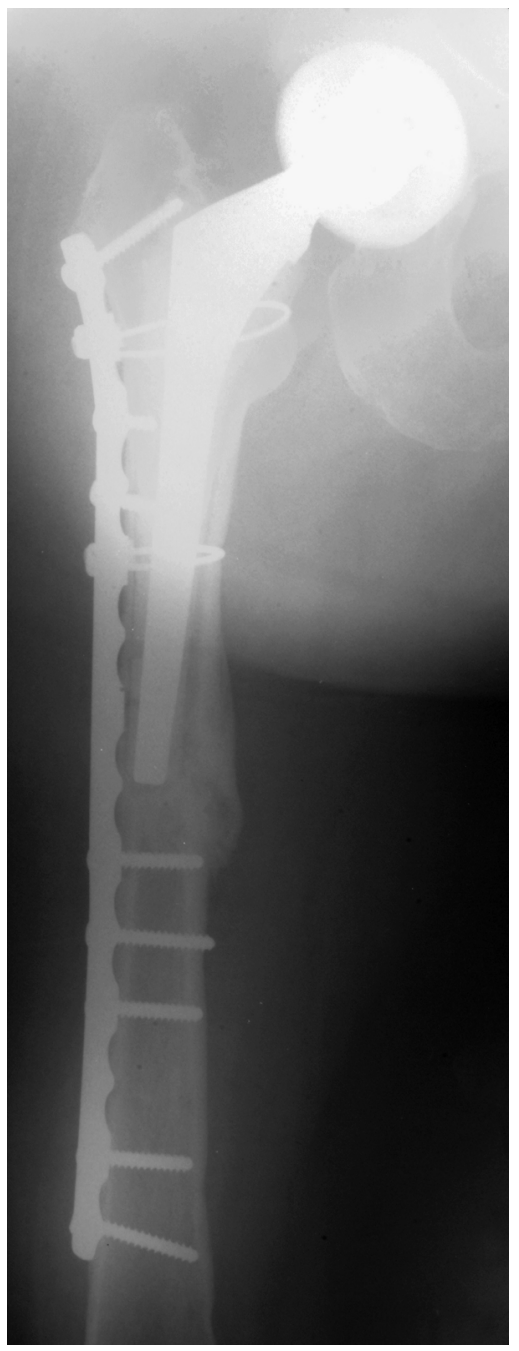

Fig. 3b
Case 13. Anteroposterior radiographs showing a) proximal screw failure and nonunion eight months after plate fixation and b) healing after a second plate fixation. with a metal plate) using Fisher's exact analysis. There was no significant difference in the rate of union or malunion for our results with plate alone and either strut allograft in isolation ( $\mathrm{p}=0.5$ and $\mathrm{p}=0.24$ for union and malunion, respectively) or strut allograft with plates $(\mathrm{p}=0.51$ and $\mathrm{p}=0.2$ for union and malunion, respectively).

\section{Discussion}

The most common type of peri-prosthetic fracture after THR occurs in the region surrounding and immediately distal to the tip of the stem, a Vancouver type-B fracture. When the femoral stem remains well fixed (Vancouver typeB1), reduction and internal fixation are recommended in most cases. ${ }^{1,3,4,9-12}$ The use of long allograft struts with cerclage wires has been advocated and supported by the results of a multi-centre study. ${ }^{2}$ These authors and others have suggested that plates may be used, but only in addition to allograft strut fixation. ${ }^{2,4,13-16}$

We have demonstrated that when bone stock is sufficient, as generally occurs in Vancouver type-B1 fractures, broad metal plate fixation without bone graft is as good as allograft strut fixation and may be preferable. Accurate reduction and stable fixation, with preservation of the blood supply and timely functional rehabilitation, lead to a high rate of early union. We recommend a specific technique for plating which includes proximal screw fixation in addition to cables, a longer plate than would commonly be used and minimal disruption of the soft-tissues at the site of the fracture.

Our results with this technique have shown that malunion can be avoided, early weight-bearing can be achieved, and the risk and expense of allograft bone do not have to be assumed. Malunion may be less common than with the use of struts because more stable fixation is obtained. ${ }^{17}$ We believe that earlier weight-bearing was achieved in our series because we had confidence in the fixation and could evaluate healing of the fracture more easily.

Plate fixation with bicortical screws distally and unicortical screws with or without cables proximally, has been 
shown in vitro to give superior stability in axial loading, lateral bending and torsional loading when compared with strut or plate fixation by cables alone or cables proximally. ${ }^{17,18}$ Furthermore, clinical results have supported this construct in vivo. ${ }^{10}$ Previously reported poor in vitro ${ }^{16}$ and in vivo ${ }^{4,19}$ results of plating alone for the treatment of periprosthetic femoral fractures can be explained by the fact that relatively short plates with insufficient proximal and distal fixation were used. Plate fixation in cases of fracture with loose stems (Vancouver type-B2 and type-B3) is inadequate and will lead to a high rate of failure. ${ }^{5,20}$ It is a practice which we do not advocate.

Some authors have pointed out several theoretical concerns about plating alone for fixation of peri-prosthetic fractures. ${ }^{2,4,13-16}$ There may be limited space for screws around the implant proximally, and this may be worse with large canal-filling, uncemented femoral components. ${ }^{1,9}$ It has been postulated that screw fixation may damage the cement mantle around a cemented femoral component, produce adverse stress risers around the screws and cause stress shielding under the plate and damage to the stem. ${ }^{16}$ To our knowledge, there have been no reports of clinical failures associated with these hypothetical situations.

Cortical allograft struts are expensive, ${ }^{21}$ may transmit disease, ${ }^{9}$ weaken as they incorporate into the host femur ${ }^{9}$ and require stripping of the femoral cortex for application. ${ }^{10}$ Avoidance of these concerns is to the patient's benefit if allograft bone is not essential.

Recommendations for peri-prosthetic fixation may require not only randomised, controlled, prospective studies for each subtype of fracture but also the collation of data from many centres.

Type-B1 peri-prosthetic femoral fractures can be satisfactorily treated by the standard AO principles of accurate reduction, stable fixation, preservation of the soft tissues and early functional rehabilitation. Plate fixation without allograft struts appears to be a safe, cost-effective method of treating such fractures. We suggest the use of relatively long broad plates with proximal and distal screw fixation in addition to proximal cerclage cables when needed. Our results with this technique are comparable to those reported for similar fractures using allograft struts alone or combined with a plate. ${ }^{2}$

Support for this work was provided by Synthes, West Chester, Pennsylvania and the Maine Joint Replacement Institute, Portland, Maine.

No benefits in any form have been received or will be received from a com mercial party related directly or indirectly to the subject of this article.

\section{References}

1. Duncan CP, Masri BA. Fractures of the femur after hip replacement. Instr Course Lect 1995;44:293-304.

2. Haddad FS, Duncan CP, Berry DJ, et al. Periprosthetic femoral fractures around well-fixed implants: use of cortical onlay allografts with or without a plate. J Bone Joint Surg [Am] 2002;84-A:945-50.

3. Brady $\mathbf{O H}$, Garbuz DS, Masri BA, Duncan CP. The reliability and validity of the Vancouver classification of femoral fractures after hip replacement. J Arthroplasty 2000;15:59-62.

4. Wilson D, Masri BA, Duncan CP. Periprosthetic fractures: an operative algorithm. Orthopedics 2001;24:869-70.

5. Lindahl H, Malchau H, Oden A, Garellick G. Risk factors for failure after treatment of a periprosthetic fracture of the femur. J Bone Joint Surg [Br]2006;88-B:2630

6. Maloney WJ, Hartford JM. The cemented femoral component. In: Callaghan JJ Rosenberg AG, Rubash HE, eds. The adult hip. Vol. 2. New York: Lippincott-Raven, 1998:959-79.

7. White RE Jr. Evaluation of the painful total hip arthroplasty. In: Callaghan JJ, Rosenberg AG, Rubash HE, eds. The adult hip. Vol. 2. New York: Lippincott-Raven, 1998:1377-85.

8. Brady OH, Kerry R, Masri BA, Garbuz DS, Duncan CP. The Vancouver classification of periprosthetic fractures of the hip: a rational approach to treatment. Techn Orthop 1999;14:107-14.

9. Brady OH, Garbuz DS, Masri BA, Duncan CP. The treatment of periprosthetic fractures of the femur using cortical onlay allograft struts. Orthop Clin North Am 1999:30:249-57

10. Ricci WM, Bolhofner BR, Loftus T, et al. Indirect reduction and plate fixation without grafting, for periprosthetic femoral shaft fractures about stable intramedullary implant. J Bone Joint Surg [Am] 2005;87-A:2240-5.

11. Stern RE, Harwin SF, Kulick RG. Management of ipsilateral femoral shaft fractures following hip arthroplasty. Orthop Rev 1991;20:779-84

12. Levenberg $\mathbf{R}$, lorio $\mathbf{R}$, Gingrich $\mathbf{K}$, Berman AT. Femur fractures associated with total hip arthroplasty. Orthopedics 1990;13:1188-9.

13. Lewallen DG, Berry DJ. Periprosthetic fracture of the femur after total hip arthroplasty: treatment and results to date. Instr Course Lect 1998;47:243-9.

14. Tsiridis E, Narvani AA, Timperley JA, Gie GA. Dynamic compression plates for Vancouver type B periprosthetic femoral fractures: a 13-year follow up of 18 cases. Acta Orthop 2005;76:531-7.

15. Wang J, Wang C. Periprosthetic fracture of the femur after hip arthroplasty: the clinical outcome using cortical strut allografts. J Orthop Surg (Hong Kong)2000;8:2731.

16. Wilson D, Frei H, Masri BA, Oxland TR, Duncan CP. A biomechanical study comparing cortical onlay allograft struts and plates in the treatment of periprosthetic femoral fractures. Clin Biomech (Bristol, Avon) 2005;20:70-6.

17. Dennis MG, Simon JA, Kummer FJ, Koval KJ, Cesare PE. Fixation of periprosthetic femoral shaft fractures occurring at the tip of the stem: a biomechanical study of 5 techniques. J Arthroplasty 2000;15:523-8.

18. Dennis MFG, Simon JA, Kummer FJ, Koval KJ, Di Cesare PE. Fixation of periprosthetic femoral shaft fractures: a biomechanical comparison of two techniques. J Orthop Trauma 2001;15:177-80.

19. Tower SS, Beals RK. Fractures of the femur after hip replacement. Orthop Clin North Am 1999;30:235-47.

20. Kamineni S, Vindlacheruvu R, Ware HE. Peri-prosthetic femoral shaft fractures treated with plate and cable fixation. Injury 1999;30:261-8.

21. Chandler HP, Tigges RG. The role of allografts in the treatment of periprosthetic femoral fractures. J Bone Joint Surg [Am] 1997;79-A:1422-32. 